\title{
Modulation Response of the Thyristor SCR (BT151) at High Frequency
}

\author{
Zead T. Ahmed Saad F. Ramadhan Hesham A. Salih \\ Department of Physics / College of Education \\ University of Mosul
}

Received

$15 / 12$ / 2008
Accepted

06 / 04 / 2009

\section{الخلصة:}

قم في هذا البهث درلسة الخصائص الاستاتيكية والدينميكية لثايوس ـتور i ـوع SCR (BT151). فيما يخص الخصائص الاستاتيكية جرى درلسة علاقة التيار فولتية لهذه النبيطة

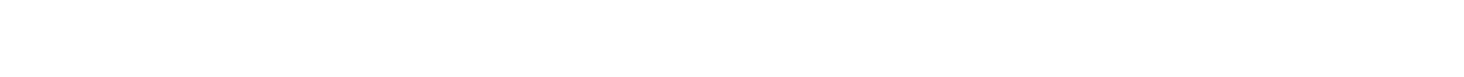

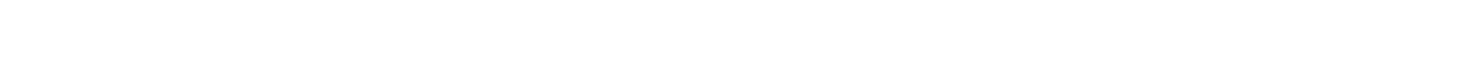

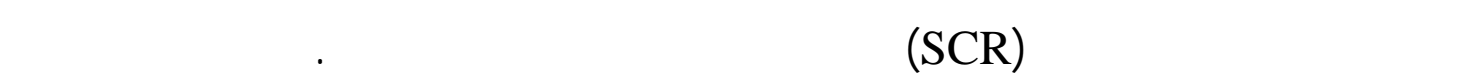

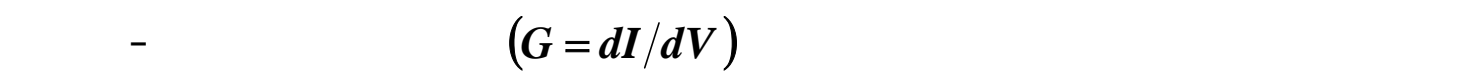
والمعلمة (dG/dV) مع تغير فولتية الانود -كاثود أيضاً.

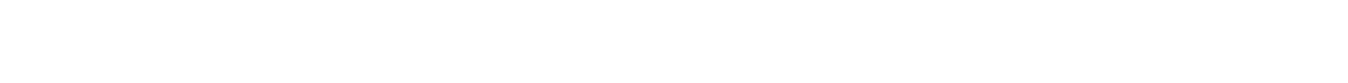

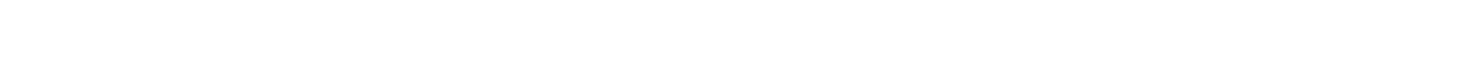

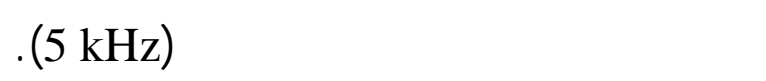

\section{Abstract :}

In this work, static and dynamical chracteristics of SCR(BT51) thyrister have been studied.In relate to static chracteristics, I-V relationship of this device has been illustrated at different temperatures as well as determination of threshold voltage values $\left(\mathrm{V}_{\text {th }}\right)$,studing it's variation as a function of temperature and the result obtaining from this study that the $\left(\mathrm{V}_{\mathrm{th}}\right)$ is nonlinearly increasing with temperature increasing, this gives the fact that the device senstive to temperature variation.Also, the relationship between both of the conductance $(\boldsymbol{G}=\boldsymbol{d I} / \boldsymbol{d V})$ and the parameter $(\boldsymbol{d} \boldsymbol{G} / \boldsymbol{d} \boldsymbol{V})$ with anode-cathode voltage variation have been explained. 
For dynamical properties of this device,the intermodulation distortion as a function of common effect between anode and gate frequencies more than $(5 \mathrm{kHz})$ has been observed.

\section{1- Introduction:}

The original thyratron driver had been designed and used since the beginning of stanford linear accelerator center (SLAC) modular operations in the middle sixties[5]. It could generate up to $5 \mathrm{kV}$ at $1.5 \mu \mathrm{s}$ pulses. However, it was large and heavy, required frequent intervention, and used PCB dielectric capacitors and unreliable thyratron and vacuum tubes[5]. In 1992, a modulator reliability improvement project was established and one phase was to replace these original drivers with solid-state trigger drivers utilizing modern components and packaging techniques[5]. Besides meeting certain electrical and mechanical requirements, the new trigger generator reliability and manufacturing cost were of major concerns. Fast and extremely stable thyratron drivers had been designed and built for the kicker system at SLAC, but they were quite expensive because of high part and assembly costs[5]. This report describes the design and performance of an economical, reliable, fast and high voltage thyratron driver.

Today's instrumentation and control operations not only demands high quality, ultrareliable power, but need it in unprecedented vast quantities and fast time frames[5].Overall, as modern economies move into the $21^{\text {st }}$ century, high - tech users are expected to demand for high SQRA (security, quality, reliability and availability) power supply. In the new and dynamic deregulated electricity environment, this is opening business opportunities for acute energy providers[1].

Reliability is the ability of the power system to supply energy within accepted standards and in the amount desired. Reliability is measured using various indices characterizing frequency, duration and magnitude of adverse effects on the electric supply. It has been recognized that measures of reliability should include some other power quality issues (such as voltage sag and dip disturbances) that are becoming increasingly significant in the digital age[1].

In this paper, we have studied the charateristics of SCR(BT151) thyristor.These charateristics include the high freqency modulation at the temperature dependence of its operation. Also some static and dynamical properties were investigated.

\section{2-Theoritical principles}

In order clarity the thyristor operation we need to introduce some its principles and the most related parameters for definite operation. 


\section{2-1 The Thyristor:}

In fact the term thyristor defines a silicon biopolar semiconductor family including any switch whose bistable action depends on PN-PN regenerative feedback. The main members of this family are the SCR and the Traic[3].

Triacs have been available since the early 1970s. They could be regarded as a mature technology. However, they remain an extremely popular power control device for AC main applications because of their low cost and the simplicity of their control circuits. Nothing can better them in these two respects. There has even been an upsurge in their use in the 1990s due partly to the proliferation of domestic appliances with electronic controls. Common examples of these include air and water heaters, vacuum cleaners, refrigerators, washing machines, dishwashers and most small kitchen appliances[6]. On the other hand, this structure is also widely used in the new product family integrating several discrete components to build various power functions. This new integrated circuits range is called $\mathrm{ASD}^{\mathrm{TM}}$ (Application Specific Discrete)[3].

In the current-voltage (I-V) characteristics, field-induced switching effects have been discovered recently in several molecular conductors. The field-induced switching effect can, in general, be attributed to the differential-negative-resistance (DNR) effect in the I-V characteristics curve of materials[8].

The switching effect originating from the DNR effect in materials is an important practical functionality for use in electronic devices such as memory or a semiconductor controlled rectifier (SCR). SCR or the socalled thyristor device, which is used in many industrial products such as inverters and power converters, has a four-layer $p-n-p-n$ structure of inorganic semiconductors[8].

There are several methods to trigger the switching effect in conventional thyristor devices. When the magnitude of the voltage between the terminals of the device exceeds a certain threshold value, the switching to a HC state can take place. This voltage triggering is the most important method of the switching of thyristor devices. The threshold voltage to induce the switching can be decreased with an increase of the current flow through a gate electrode on the device. Light irradiation can also change the threshold voltage decreases with an increase of the light intensity. Using the light triggering method, we can electrically isolate the triggering circuit from the switching circuit composed of the $p-n-p-n$ structure. Owing to this technical advantage, the light triggering method is widely utilized in high-current switching units. Further, this triggering method is required to construct optoelectronic devices such as optical switchers, which are utilized as building blocks in an optical information processing. The thyristor devices employing the light triggering method are often called the light-activated thyristor[8]. 


\section{2-2 Main Characteristics and Benefits:}

\section{A- Benefits:}

Due to these specific characteristics and properties SCR's and triacs offer to the designer substantial benefits such as:[3]

- Easy to drive.

- Low consumption drive circuit.

- Ideal switch for pulse operation (ex. Discharge of capacitor).

- Automatic switching off.

- Reverse polarity protection (SCR).

- Bidirectional switch-current and voltage-(traic).

- High ruggedness.

\section{B- Gate Trigger Current $\mathrm{I}_{\mathrm{GT}}$ :}

Phillips D and E series triacs are specified to trigger in all four quadrants. However, a feature of four-quadrant triacs is that they are less sensitive and more difficult to trigger in the $4^{\text {th }}\left(\mathrm{T} 2-\mathrm{G}^{+}\right)$quadrant. (For example, for the $\mathrm{D}$ series, max $\mathrm{I}_{\mathrm{GT}}$ in quadrant $1,2,3,4$ is $5,5,510 \mathrm{~mA}$ and for the E series it is $10,10,10,24 \mathrm{~mA})$. The ability of triacs to support a high rate of rise of load current $\left(\mathrm{dI}_{\mathrm{T}} / \mathrm{dt}\right)$ after turn-on is also limited in the $4^{\text {th }}$ quadrant. $\left(\mathrm{dI}_{\mathrm{T}} / \mathrm{dt}\right.$ is $10 \mathrm{~A} / \mu$ s compared with $50 \mathrm{~A} / \mu \mathrm{s}$ in the other three quadrants). For these two reasons, operation in the $4^{\text {th }}$ quadrant is not recommended if it can be avoided.[6]

\section{2-3 Minimum Triac Drive Current Calculation:}

Because the current demand must be minimized in many IC application, it is necessary to calculate the gate pulse duration to be just long enough to guarantee triac triggering while avoiding unnecessary burden on the IC's power supply. The time to reach $\mathrm{I}_{\mathrm{L}}$, hence the gate pulse duration, can be calculated using the equation:[6]

$$
I_{L}=I_{p k} \times(2 \pi f) \times \sin ^{-1}\left(I_{L} / I_{p k}\right)
$$

Transposing gives:

$$
t=1 /(2 \pi f) \times \sin ^{-1}\left(I_{L} / I_{p k}\right)
$$

The average gate current supplied by the IC is calculated by multiplying its peak gate current with $\mathrm{t} / \mathrm{T}$. Hence:

$$
I_{G(\text { ave })}=I_{G(p k)} \times t / T
$$

$\mathrm{I}_{\mathrm{L}}=$ triac latching current at the lowest expected operating temperature.

$\mathrm{I}_{\mathrm{pk}}=$ peak load current.

$\mathrm{t}=$ gate pulse duration

$\mathrm{T}$ = gate pulse cycle time

Note: Since triac latching current is higher in the $2^{\text {nd }}$ and $4^{\text {th }}$ quadrants, and normal operation for IC triggering is in the $2^{\text {nd }}$ and $3^{\text {rd }}$ 
quadrants, the gate current calculations must always be based on the worst case quadrant $2 \mathrm{I}_{\mathrm{L}}$ condition.[6]

If the load current is very low and the necessary gate pulse duration imposes too great a burden on the IC's power supply, triggering could be delayed for a few degrees to allow the supply voltage to build up a little. The time to reach IL will then be shortened by the delay time (true for resistive loads). Now that switching occurs further from the zero crossing, there will be a slightly increased risk of RFI generation, even if the load current is very low as in this case. RFI measurements will show if filtering is necessary to meet the relevant EMC legislation.[6]

\section{2-4 Calculation of heatsink size}

To calculate the required heatsink thermal resistance for a given triac and load current, we must first calculate the power dissipation in the triac using the following equation:[6]

$\mathbf{P}=\mathbf{V}_{\mathbf{0}} \times \mathbf{I}_{\mathrm{T}(\mathrm{AVE})}+\mathbf{R}_{\mathrm{s}} \times \mathbf{I}_{\mathrm{T}(\mathrm{RMS})}{ }^{2}$

Knee voltage $V_{o}$ and slope resistance $R_{s}$ are obtained from the relevant $\mathrm{V}_{\mathrm{T}}$ graph in data book SC03. If the values are not already provided, they can be obtained from the graph by drawing a tangnt to the max $V_{T}$ curve. The point on the $V_{T}$ axis where the tangent crosses gives $\mathrm{V}_{\mathrm{o}}$, while the slope of the tangent $\left(\mathrm{V}_{\mathrm{T}} / \mathrm{I}_{\mathrm{T}}\right)$ gives $\mathrm{R}_{\mathrm{s}}$. [6]

Using the thermal resistance equation given above: $R_{\text {th } j-a}=T / P$

The max allowable junction temerature rise will be when $T_{i}$ reaches $T_{j}$ max in the highest ambient temperature.this gives us $T$.

$\mathbf{R}_{\text {th j-a }}=\mathbf{R}_{\text {th j-mb }}+\mathbf{R}_{\text {th mb-h }}+\mathbf{R}_{\text {th h-a }}$

SC03 data gives us the values for $R_{\text {th }}$ j-mb and $R_{\text {th mb-h }}$ for our chosen mouting method, leaving $\mathrm{R}_{\text {th h-a }}$ as the only unknown.[6]

\section{3- Experimental part}

Static characteristics have been measured for SCR (BT151) thyrister through circuts shown below (Fig.1-a), We applied a range of anode-cathode voltage $\left(\mathrm{V}_{\mathrm{AK}}\right)$ and measured anode current $\left(\mathrm{I}_{\mathrm{A}}\right)$ values at a specific temperature then we obtained the curve that represents the relationship between $\left(V_{A K} \& I_{A}\right)$. They have been repeated for four different temperatures.From these curves, the threshold voltages $\left(\mathrm{V}_{\mathrm{th}}\right)$ have been determined.

For studying the dynamical properties of this type of thyristers we used the circuit shown in (Fig 1-b). Dynamical properties includes applying high freqencies to study the modulation distortions on this thyrister. First, constant value of frequency has been applied at gate pole of the thyrister through the oscillator(O1) then the frequency applied on anode pole has been changed in the range $(50 \mathrm{kHz}-1 \mathrm{MHz})$ through the oscillator (O2), the result modulation shape can be observed by using spectrum analyzer. This procedure can be repeated by applying anther 
constant gate frequency. To study the influence of anode frequency on gate frequency, a constant value of anode frequency has been applied.In oppsite side a specific range of gate frequency has been applied.Also this procedure can be repeated again with different value of anode frequency.
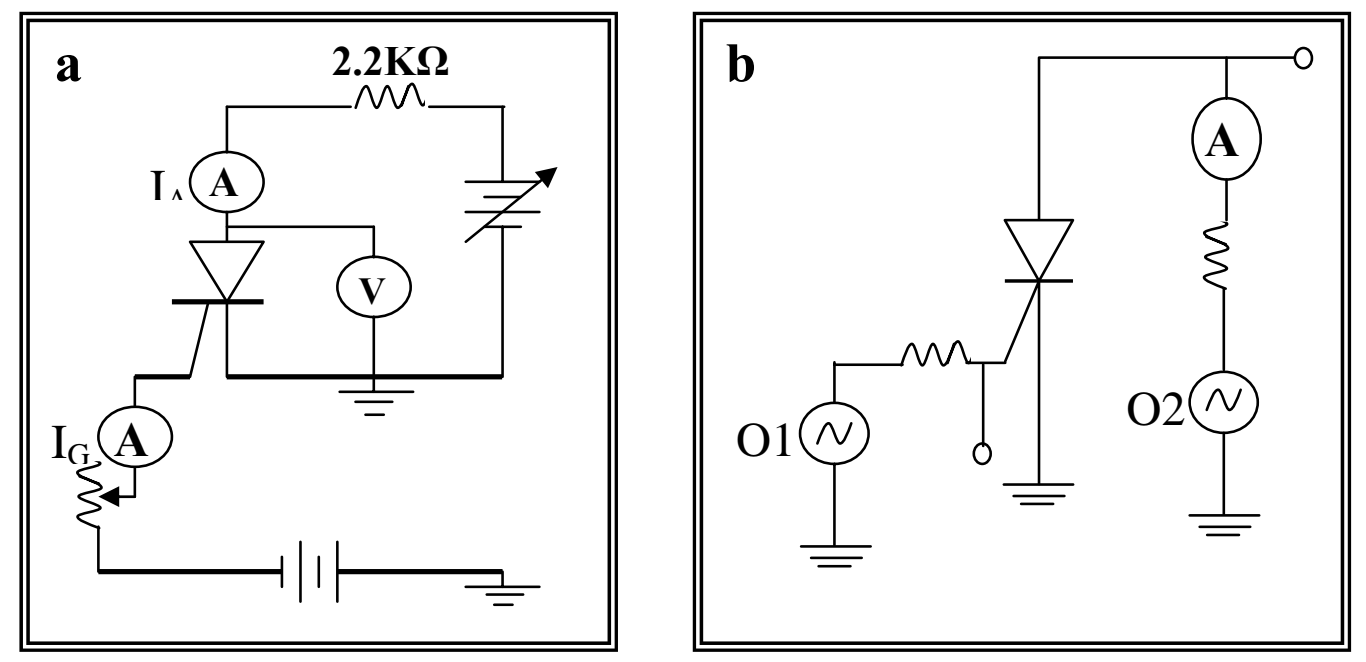

Fig.1: a- circut for measuring static charachteristics. b- circut for studing dynamical properties.

\section{4- Results and Discussion}

Fig(2) illustrate current-voltage chcaracteristics of the thyristor at different temperatures. Anode current reaches its threshold value of anode-cathode voltage $\left(\mathrm{V}_{\text {th }}\right)$ at higher value when temperature was increased. Threshold voltage of the device relates its internal parameters dependence. Perhaps the influence of (doping, barrier, kind of semiconductor 'energy gap') have been illustrated in $V_{\text {th. Linear }}$ dependence of current-voltage characteristics was observed in all the plotted results giving an ohmic relationship.

In order to empharised the relationship between $\mathrm{V}_{\text {th }}$ and temperature, we have plotted the calculated values of $V_{\text {th }}$ versus the temperature, as seen in Fig(3).

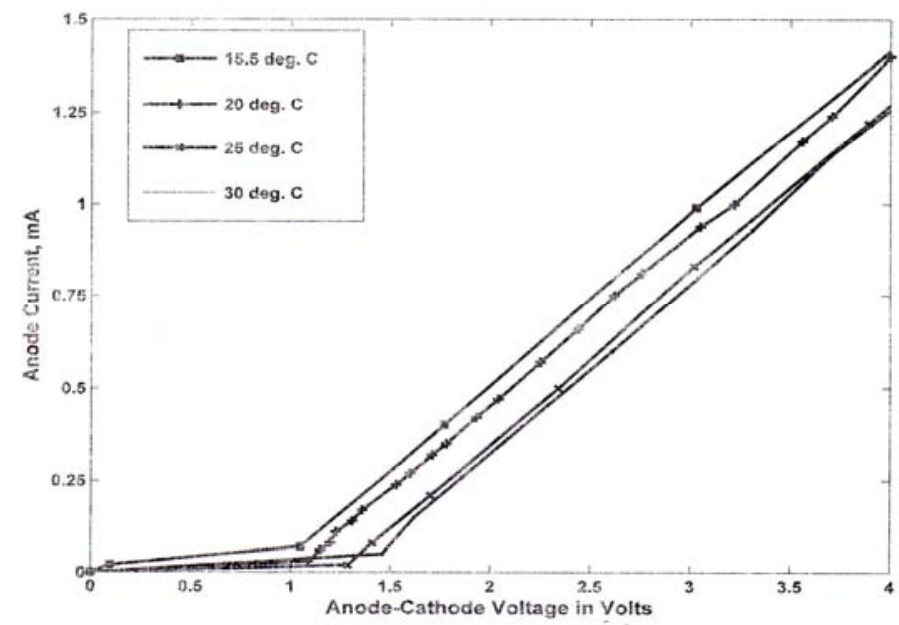

Fig.2: $I_{A}-V_{K A}$ characteristics of SCR (BT151) 


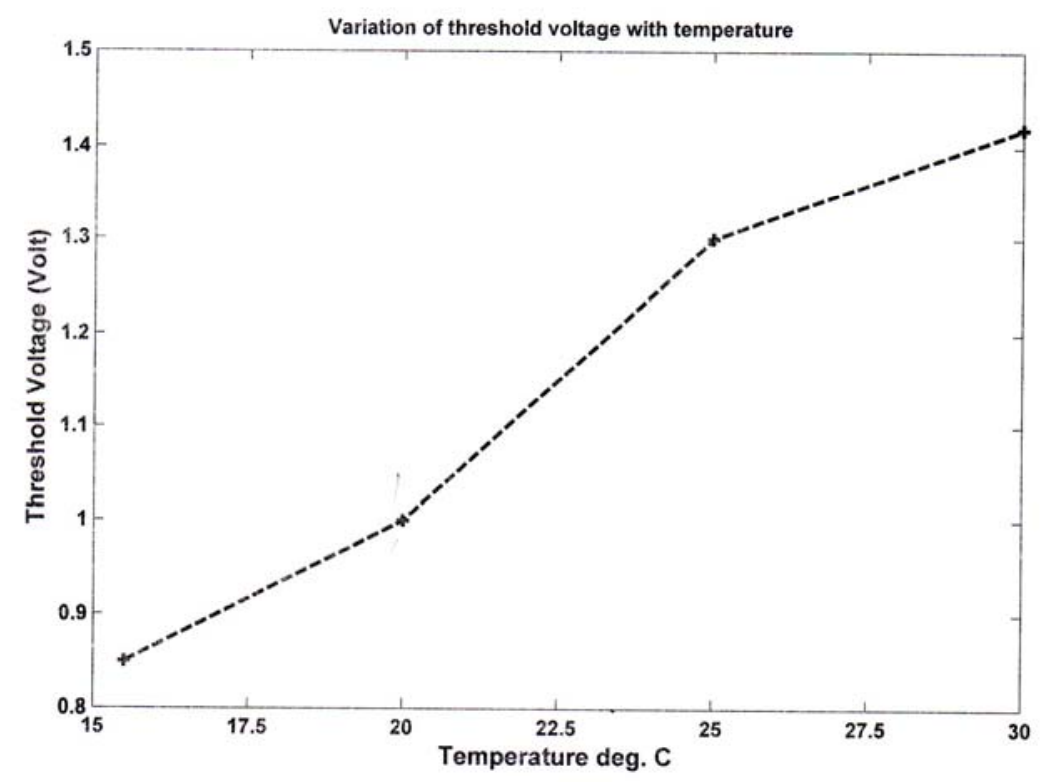

Fig.3: Threshold voltage as a function of temperature.

The figure shows a nonlinear relationship between $V_{\text {th }}$ and temperature.The fitting relation between them is given below:

$V_{t h}=a_{\circ}+a_{1} \cos (T . w)+b_{1} \sin (T . w)$

with the coefficients are given as:

$$
\begin{aligned}
& \mathrm{a}_{0}=1.152 \\
& \mathrm{a}_{1}=0.2426 \\
& \mathrm{~b}_{1}=0.1401 \\
& \mathrm{w}=0.2324
\end{aligned}
$$

This relationship is more likely for this kind of device.

For analytical deployment of the anode current dependence on the anode-cathode voltage,we have used the matlab package to obtain the first and second derivative for each case. For the data set of (I vs V) at the temperatures of $\left(15.5{ }^{\circ} \mathrm{C} \& 30{ }^{\circ} \mathrm{C}\right)$ is showen in Fig(4) and Fig(7) respectively. It is clear for the plot of first derivative that a peak value at $\mathrm{V}_{\mathrm{th}}$. Also, the curve shows some instabilities due to the fluctuation of the current due to tepmerature control. First derviative, as we know gives the conductance $(G)$ of the device. Second derivative illustrates the variation $(\boldsymbol{d} \boldsymbol{G} / \boldsymbol{d} \boldsymbol{V})$ against the voltage and it was found to be stable.In Fig(5) at $\left(20{ }^{\circ} \mathrm{C}\right)$, the curve that represent first derviative shows instabilities due to the fluctuation of the current because of tepmerature variation but in Fig(6) we saw that the $(\boldsymbol{d I} / \boldsymbol{d} \boldsymbol{V})$ be vary stable at $\left(25^{\circ} \mathrm{C}\right)$.Also,second derivative illustrates the variation $(\boldsymbol{d} \boldsymbol{G} / \boldsymbol{d} \boldsymbol{V})$ against the voltage and shows high fluctuation in $(\boldsymbol{d} \boldsymbol{G} / \boldsymbol{d} \boldsymbol{V})$ value in both of Fig(5) and Fig(6). 
Modulation Response of the Thyristor SCR (BT151) at High Frequency.

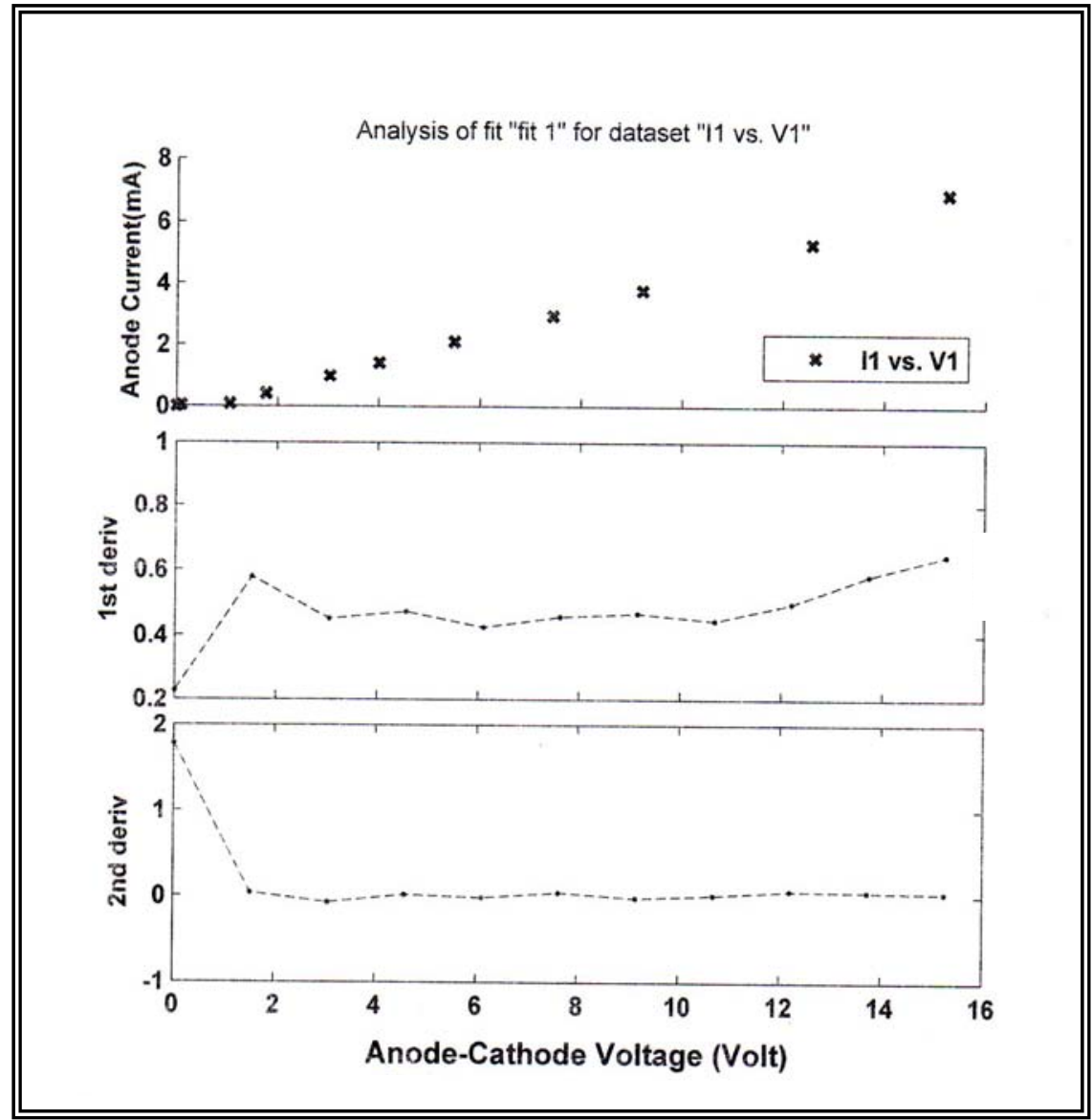

Fig.4: $1^{\text {st }} \& 2^{\text {nd }}$ derivative for $\mathrm{I}-\mathrm{V}$ curve at $15.5{ }^{\circ} \mathrm{C}$

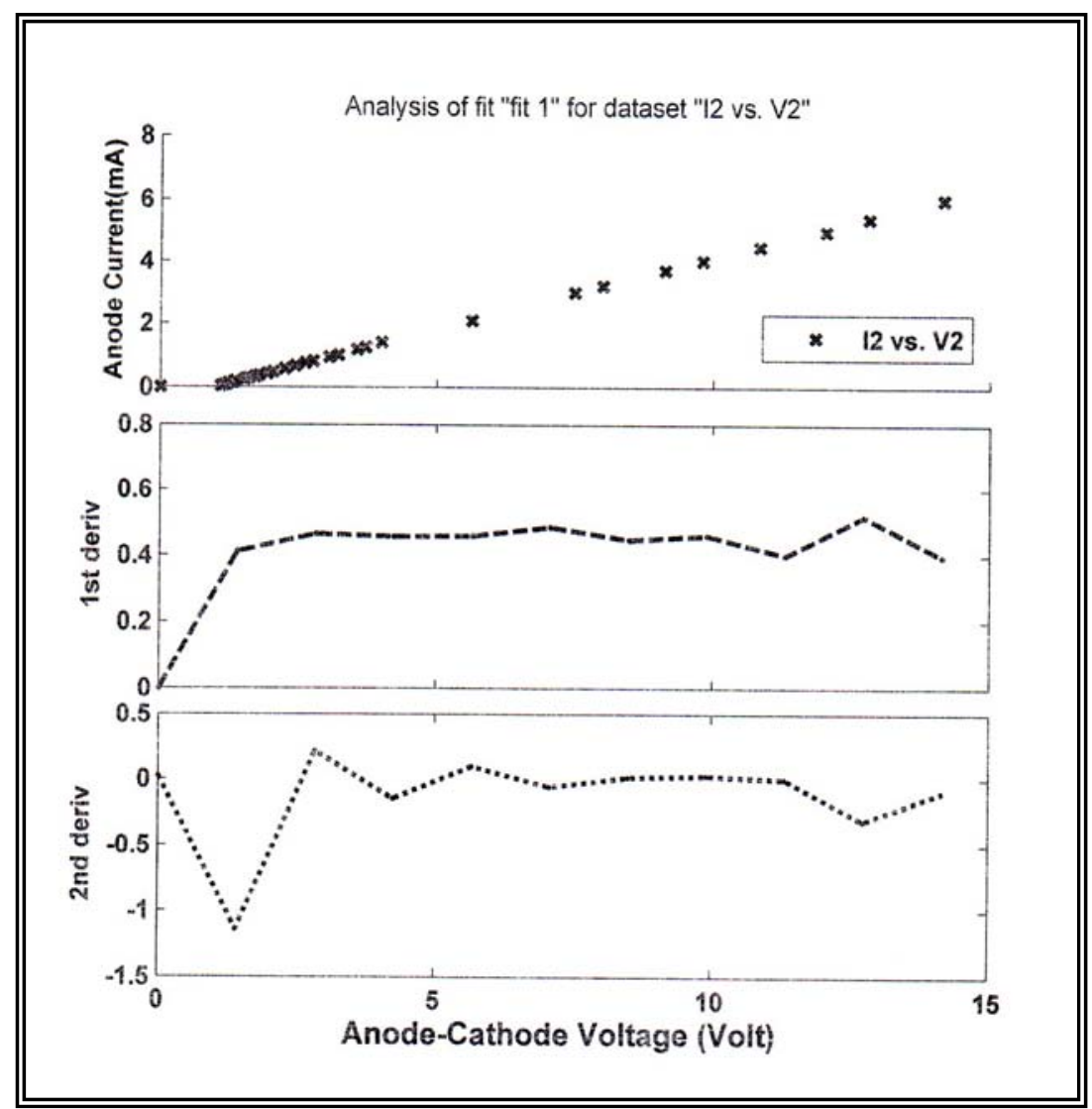

Fig.5: $1^{\text {st }} \& 2^{\text {nd }}$ derivative for $\mathrm{I}-\mathrm{V}$ curve at $20^{\circ} \mathrm{C}$ 


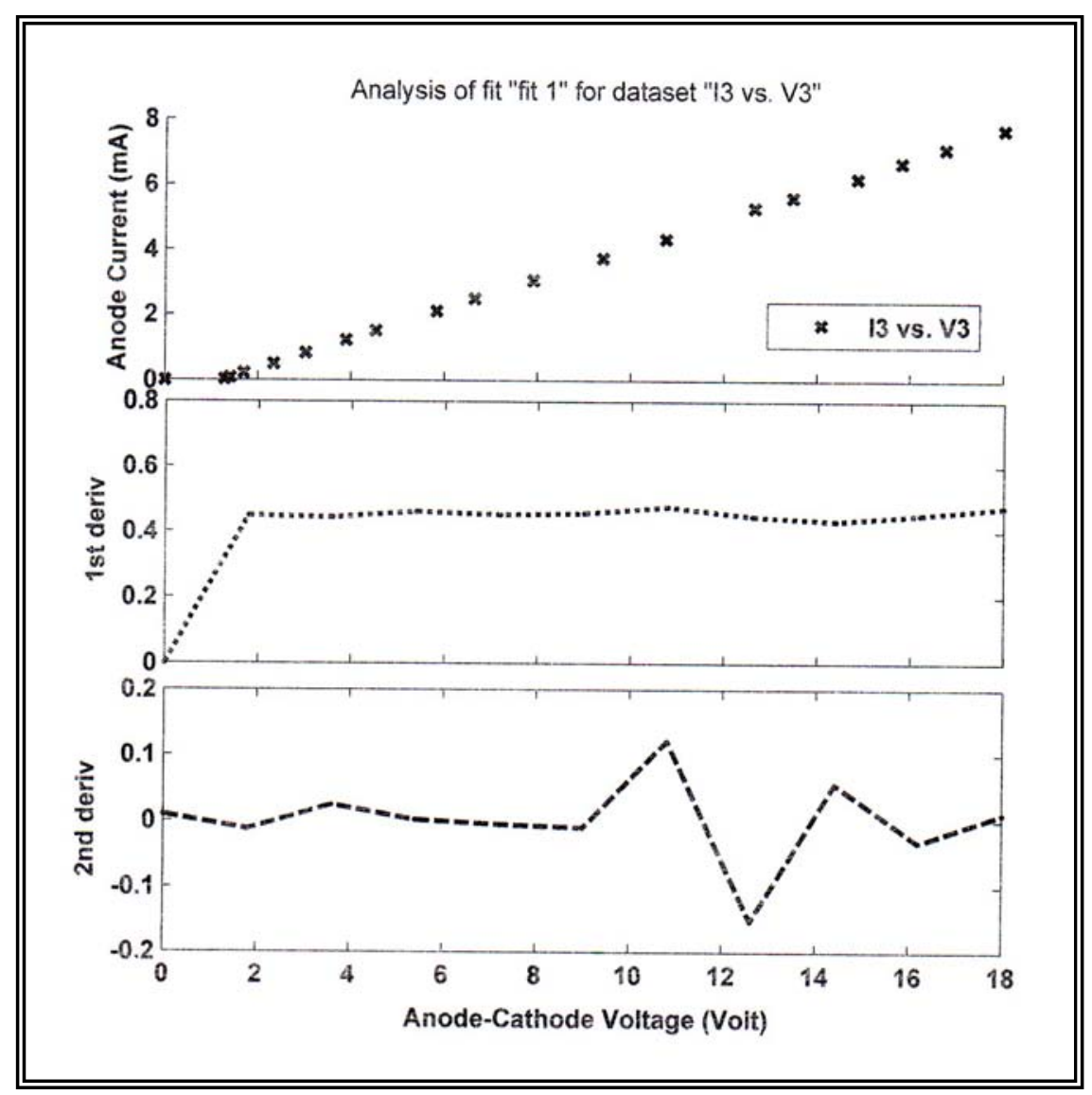

Fig.6: $1^{\text {st }} \& 2^{\text {nd }}$ derivative for $\mathrm{I}-\mathrm{V}$ curve at $25^{\circ} \mathrm{C}$

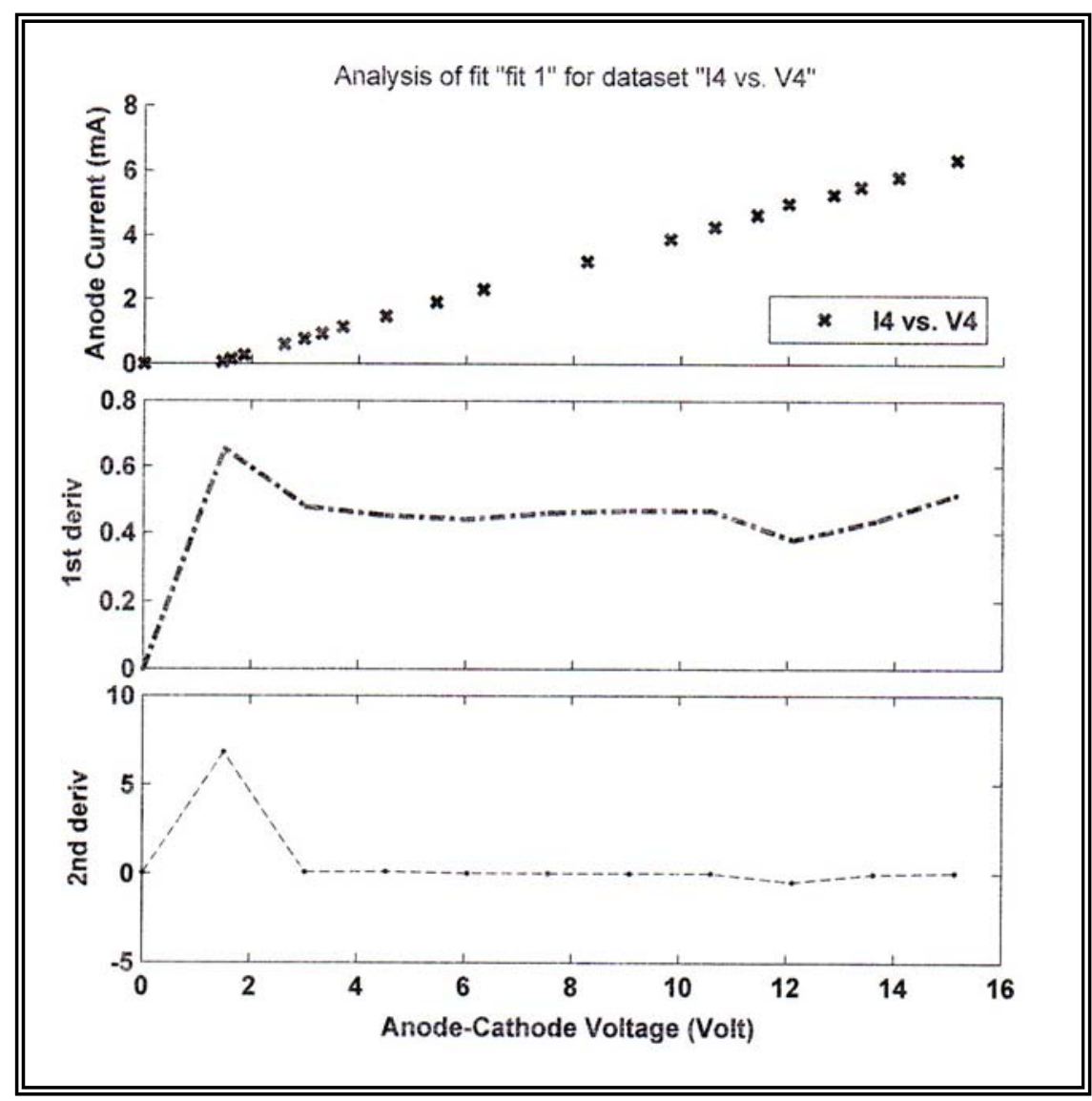

Fig.7: $1^{\text {st }} \& 2^{\text {nd }}$ derivative for $\mathrm{I}-\mathrm{V}$ curve at $30{ }^{\circ} \mathrm{C}$ 
To study the modulation characteristics of the device at frequency around $(2 \mathrm{MHz})$. Keeping the gate frequency constant at some values, e.g. ( $50 \mathrm{~Hz}, 500 \mathrm{~Hz}, 1 \mathrm{MHz}$ ) the frequency applied to the anode was varried as showen in Fig(8).

It is clear that, as the anode frequency was increased, the noise level was decreased and the anode starts to develope its harmonics very sharply employing a good. As can been seen from the Fig(8), as the anode frequency was increased more pronounced, peaks have been developed and bandwidth/amplitude were also varied due to this increasing. Gate voltage and frequency have to be related to the anode frequency with chip parameters obtained from the data sheet.

Fig(9) illustrates the influence of gate frequency on the anode modulation function when the anode was kept constant at $(1 \mathrm{MHz})$. The frequency of the gate was varried as showen in the gragh. Intermodulation distortion was observed the sepctrum of the anode which indicates that the gate had affected the anode modulation transfer function. Anode frequency and voltage were kept constant while gate frequency was applied at different values. Anode amplitude of the harmonic had been shown clearly difference when gate frequency was increased. 


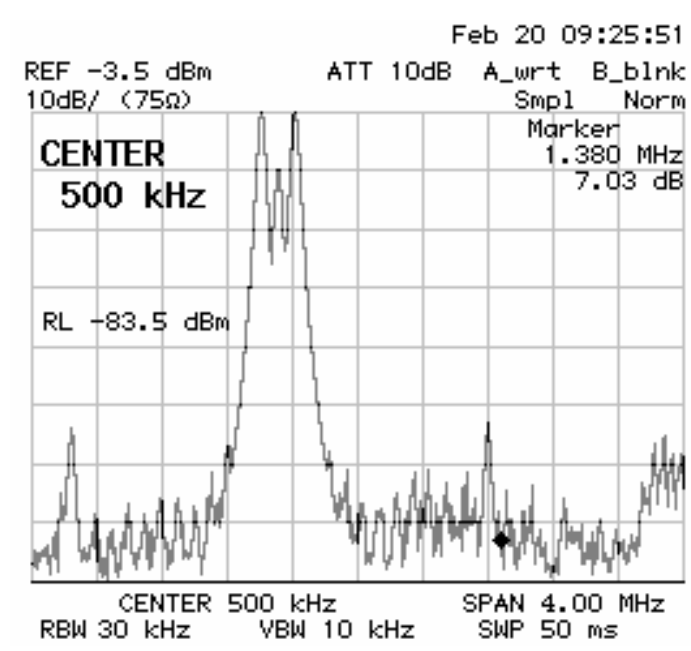

$\mathrm{FG}=50 \mathrm{kHz}, \mathrm{FA}=100 \mathrm{kHz}$

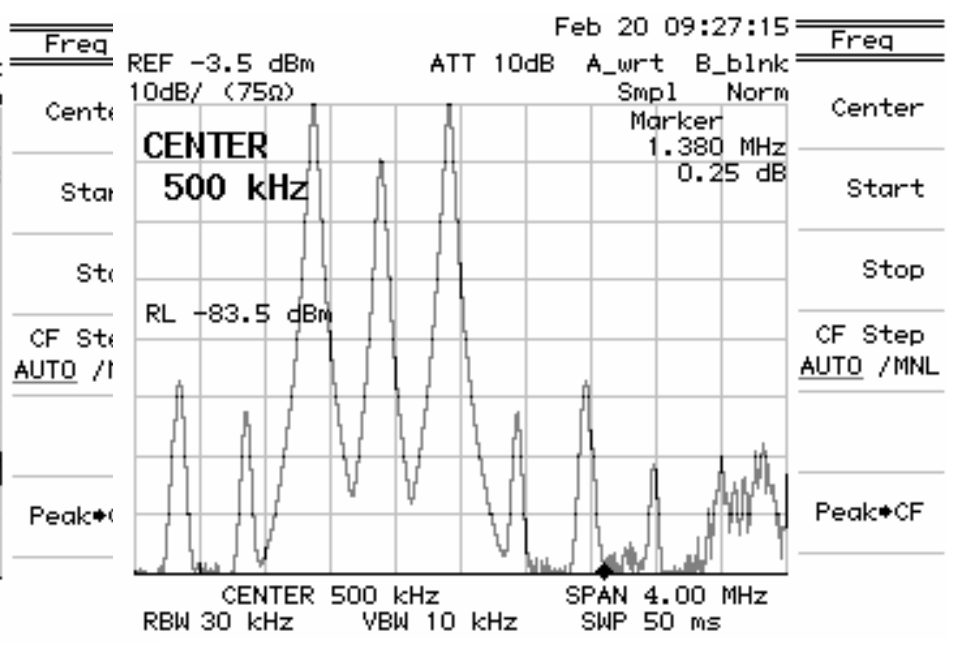

$\mathrm{FG}=50 \mathrm{kHz}, \mathrm{FA}=100 \mathrm{kHz}$

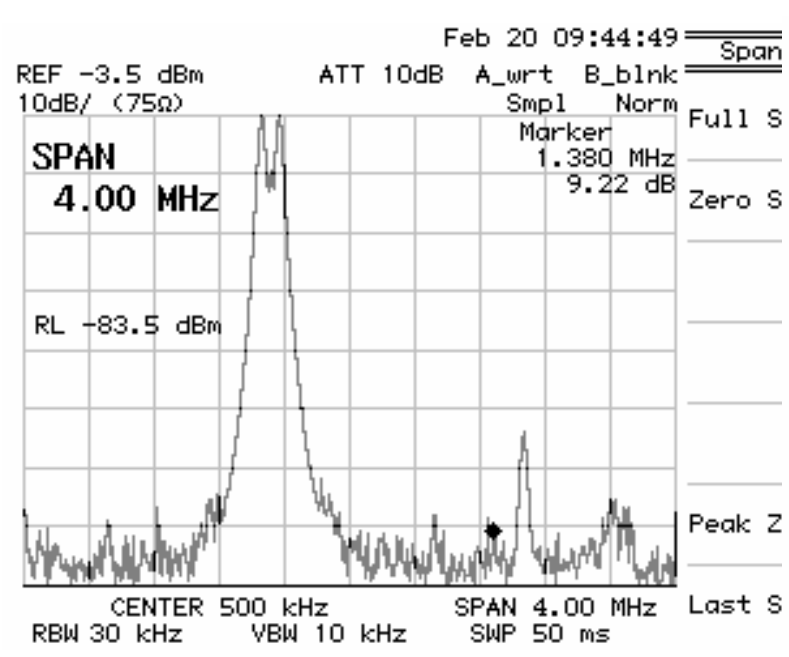

$$
\mathrm{FG}=500 \mathrm{kHz}, \mathrm{FA}=\mathbf{5 0} \mathrm{KHz}
$$

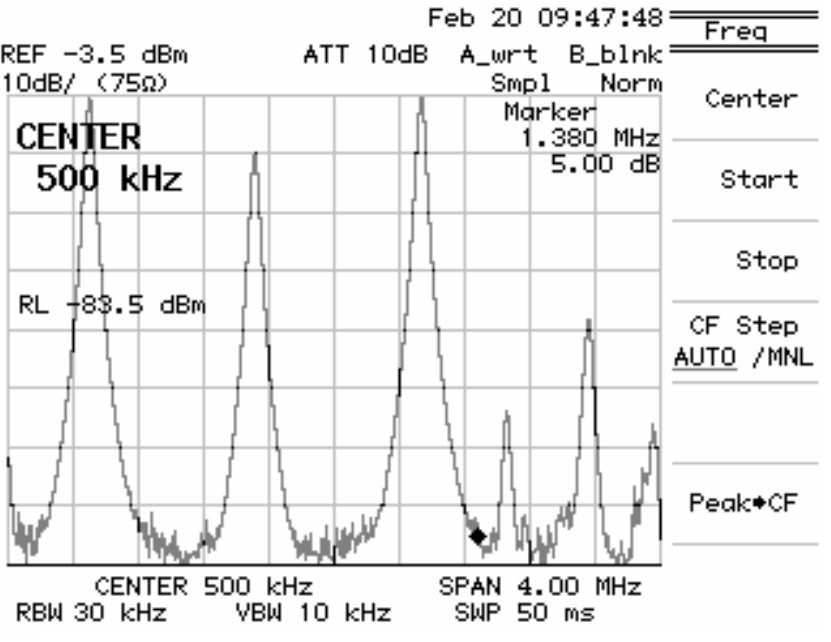

$\mathrm{F}_{\mathrm{G}}=500 \mathrm{kHz}, \mathrm{F}_{\mathrm{A}}=1 \mathrm{MHz}$

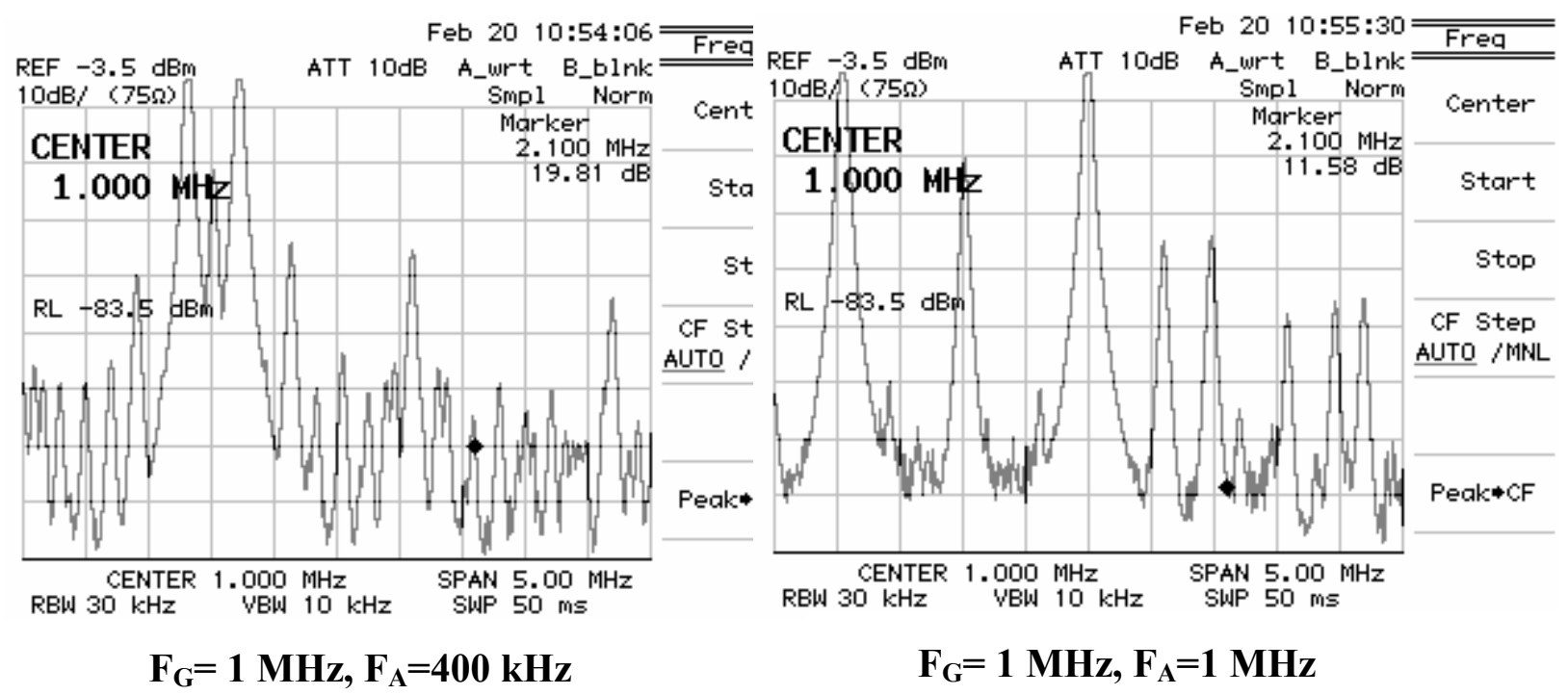

Fig.8: Anode ferquency variation as a function of gate frequency. 
Modulation Response of the Thyristor SCR (BT151) at High Frequency.

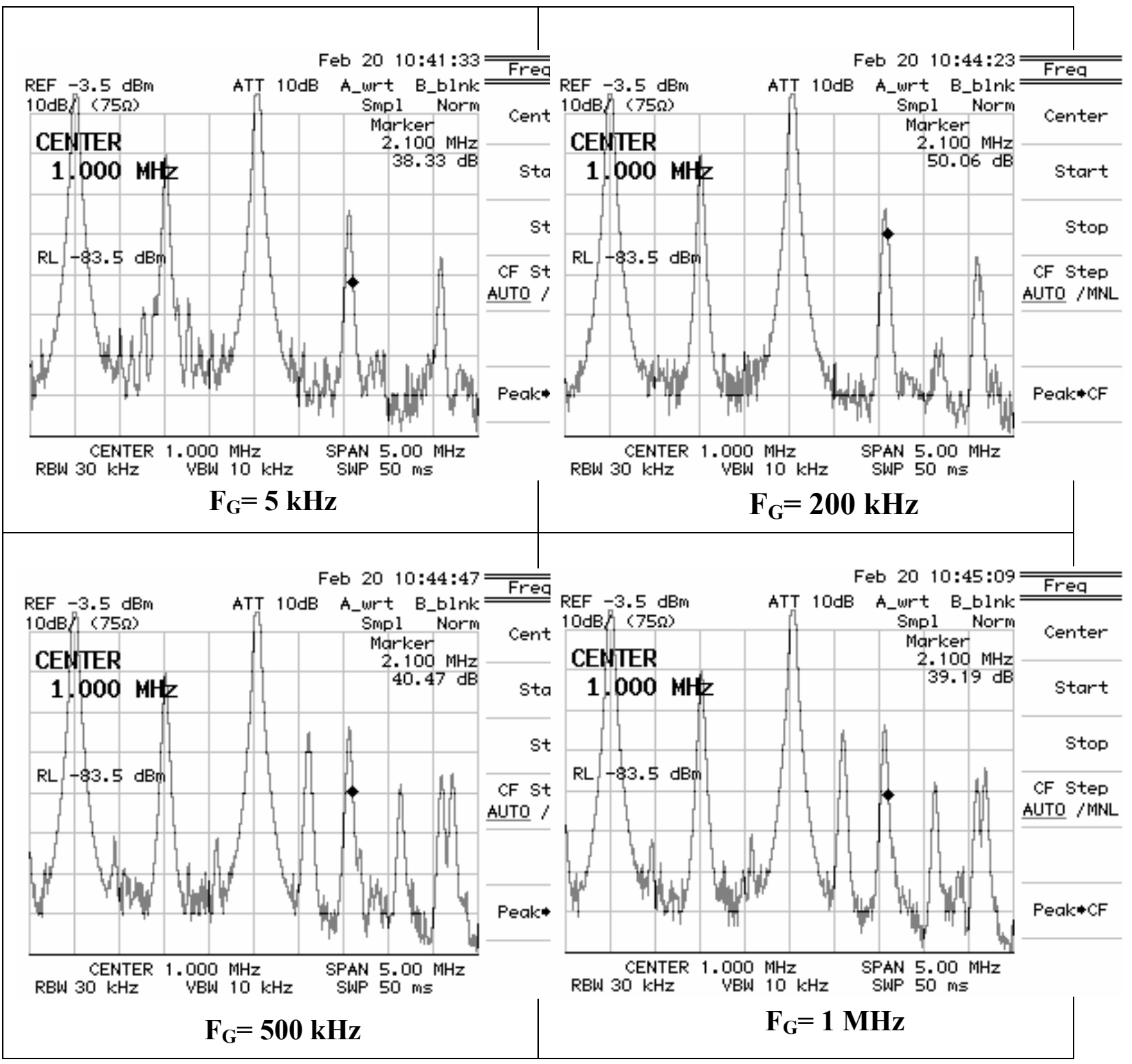

Fig.9: Gate ferquency variation as a function of anode frequency $\left(\mathrm{F}_{\mathrm{A}}=1 \mathrm{MHz}\right)$.

\section{5- Conclusions}

static and dynamical chcaracteristics of the SCR(BT151) were studied and few interesting results were obtained.

1. The influence of temperature was clearly observed on its currentvoltage characteristics.

2. intermodulation distortion was observed also when the gate was driven by applied frequency higher than $5 \mathrm{kHz}$. 


\section{References}

1) Antonio M. M. and Juan G. J., "Analysis of Power Quality in HighTech facilities" Elect. Pow. Qualit. \& Utilis. Mag., Vol.1, No.2, Spain, 2005.

2) Application Note AN-3008, "RC Snubber Networks for Thyrister power Control and Transient Suppression", www.fairchildsemi.com, 2002.

3) Application Note AN-871, www.st.com.

4) Cristal control Ltd, Canada, www.cristalcontrols.com, 2008.

5) Nguyen M. N., "fast SCR Thyratron Driver", standford linear Acceleration center, Standford, California 94309, USA.

6) Thyrister and Triacs Technecal Publications,published by Factsheet067 Logic Level and Sensitive Gate Triacs.

7) Thyrister-Wikipedia the free encyclopidia,www.wikiedia.org.

8) Toshifumi L., Nobuhiro O. and Toshio N. "Molecular-based lightActivated thyrister", Appl Phys Letters 90, pp(15-17), 2007. 